\title{
Response Reduction of Two DOF Shear Structure Using TMD and TLCD by Considering Absorber Space Limit and Fluid Motion
}

\author{
Lovely Son ${ }^{1, a^{*}}$, Mulyadi Bur ${ }^{1, b}$ and Meifal Rusli ${ }^{1, c}$ \\ ${ }^{1}$ Structural Dynamic Laboratory, Mechanical Engineering Department, \\ Engineering Faculty, Andalas University, Indonesia \\ alovelyson@ft.unand.ac.id, ${ }^{b}$ mulyadibur@ft.unand.ac.id, ${ }^{c}$ meifal@ft.unand.ac.id
}

Keywords: vibration, absorber, TMD, TLCD, GA.

\begin{abstract}
A Combination of dynamic vibration absorbers (DVAs) consist of Tuned Mass Damper (TMD) and Tuned Liquid Column Damper (TLCD) for reducing vibration response of a two-DOF shear structure model is proposed. The absorber parameters are optimized using Genetic Algorithm (GA). The cost function is derived from the ratio between structure response and the excitation signal. The limitation in absorber space and fluid motion are considered during optimization process. The simulation results show that GA optimization procedure is effective to get the optimal absorber parameters in the case of limited absorber size and motion.
\end{abstract}

\section{Introduction}

When a large earth quake occurred in West Sumatera, Indonesia in 2009, many buildings had collapsed due to a large dynamic load received by its structure and foundation. Field observation has shown that two stories buildings or larger experienced more serious damage in comparison to one story buildings. This is not surprisingly that the stiffness of multistories buildings is lower than that of one story buildings.

Theoretically, the critical condition occurred when the earthquake excitation frequency range is closest to one of the structural natural frequency[1,2]. For a two stories building, the lower natural frequencies are relating to its bending modes. Therefore, the $1^{\text {st }}$ and $2^{\text {nd }}$ bending modes of the structure are the most dominant modes that contribute to the response of the structure. As the consequence, attenuation of the structural response could be effectively achieved by reducing the frequency responses which located near to the $1^{\text {st }}$ and $2^{\text {nd }}$ natural frequencies of the structure.

In this research, two dynamic vibration absorbers are combined for reducing the vibration response of two stories building. The building is modelled as a two-DOF shear structure. The model of two-DOF shear structure with TLCD and TMD vibration absorber is shown in Fig.1. TMD and TLCD absorbers are located at the second mass of the structure. The first absorber, a TLCD system is aimed for reducing the vibration response closest to the $1^{\text {st }}$ natural frequency of the structure and the second one is a TMD system for attenuating the vibration response closest to the $2^{\text {nd }}$ natural frequency.

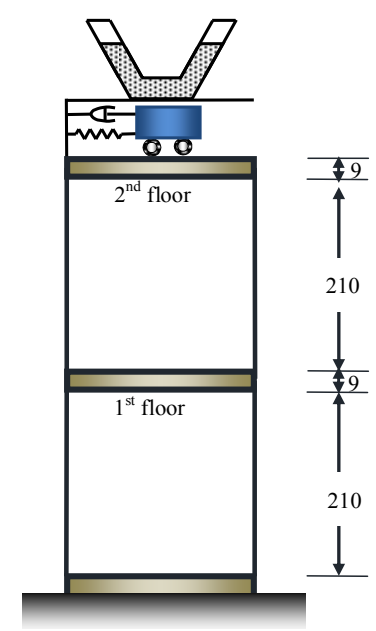

Figure 1. Two-DOF shear structure with DVA 
Due to the limitation in the absorber space and fluid motion, the optimization should be conducted to get an appropriate absorber size which resulting effective performance. In this research, the genetic algorithm (GA) procedure is utilized to calculate the optimum absorber parameters by considering the available absorber space and fluid motion.

\section{Sistem Modelling}

The governing equation of two-DOF shear structure with dynamic vibration absorber is derived using Fig.2. The reaction forces from TMD and TLCD absorbers are given by $F_{x 1}$ and $F_{x 2}$, respectively. The equation of motion for a TMD absorber is given by

$$
m_{d}\left(\ddot{x}_{0}+\ddot{x}_{d}\right)-F_{x 1}=0
$$

The interaction between TMD and the structure occurs via viscous damping and stiffness components. These interaction forces are given by

$$
F_{x 1}=c_{d}\left(\dot{x}_{2}-\dot{x}_{d}\right)+k_{d}\left(x_{2}-x_{d}\right)
$$

$x_{1}, x_{1}$ and $x_{d}$ in Fig.2 are the relative displacement of $m_{1}, m_{2}$ and $m_{d}$ to the base and $x_{0}$ is the base displacement due to the earthquake excitation.

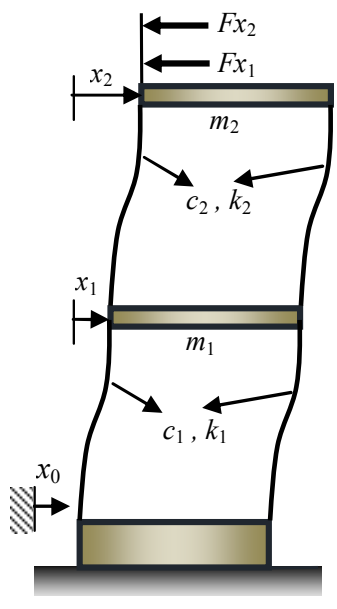

(a)

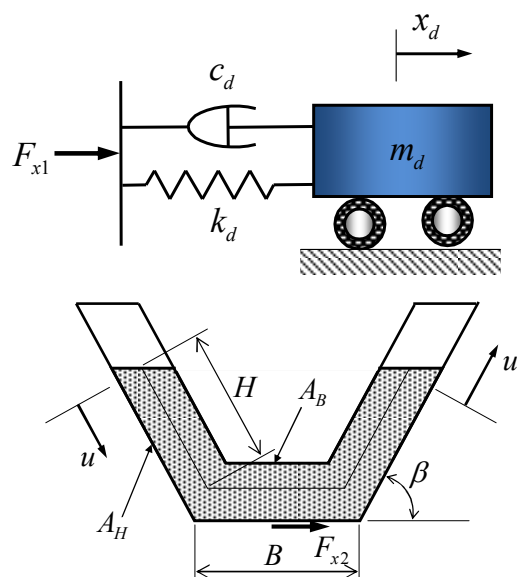

(b)

Figure 2. Modelling of two-DOF building with DVA

The governing equation the fluid motion inside the TLCD is derived by applying the modified Bernoulli equation along the relative non-stationary streamline in the moving frame[3]. This yield TLCD equation of motion as given by

$$
\ddot{u}+2 \zeta_{A} \omega_{A} \dot{u}+\omega_{A}^{2} u=-\kappa\left(\ddot{x}_{0}+\ddot{x}_{2}\right)
$$

Where

$$
\kappa=\frac{B+2 H \cos \beta}{L_{e f f}}, L_{e f f}=2 H+\frac{A_{H}}{A_{B}} B, \quad \zeta_{A}=\frac{4 U_{0} \delta_{L}}{3 \pi}
$$

$\kappa$ and $L_{\text {eff }}$ in Eq.(4) denote the geometry dependent coupling factor and the effective length of the liquid column. $\delta_{L}$ is the head lost coefficient due to turbulences along the relative streamline and additional loses due to the built in orifice. The circular eigenfrequency of the undamped TLCD is given by

$$
\omega_{A}=\sqrt{\frac{2 g \sin \beta}{L_{e f f}}}
$$


Having established the equation of motion for the TLCD, the next step is determination of the horizontal component of the interaction forces. By using the conservation of momentum applied to a virtual, massless container with fluid mass $m_{f}$ yields the horizontal component of external force acting on the fluid body

$$
F_{x 2}=m_{f}\left(\ddot{x}_{0}+\ddot{x}_{2}+\bar{\kappa} \ddot{u}\right), \quad \bar{\kappa}=\frac{B+2 H \cos \beta}{L_{1}}, m_{f}=\rho\left(2 H A_{H}+B A_{B}\right)=\rho A_{H} L_{1}
$$

By neglecting the undesired bending moment due to the eccentricity of the interaction force, the linear equation of motion of the main structure can be written by

$$
\begin{aligned}
& m_{1}\left(\ddot{x}_{0}+\ddot{x}_{1}\right)+c_{1} \dot{x}_{1}+k_{1} x_{1}+c_{2}\left(\dot{x}_{1}-\dot{x}_{2}\right)+k_{2}\left(x_{1}-x_{2}\right)=0 \\
& m_{2}\left(\ddot{x}_{0}+\ddot{x}_{2}\right)-c_{2}\left(\dot{x}_{1}-\dot{x}_{2}\right)-k_{2}\left(x_{1}-x_{2}\right)+F_{x 1}+F_{x 2}=0
\end{aligned}
$$

By combining Eqs.(1)-(8) then the equation of motion of the structure with two dynamic vibration absorber can be expressed by

$$
\begin{aligned}
& {\left[\begin{array}{cccc}
m_{1} & 0 & 0 & 0 \\
0 & m_{2}+m_{f} & 0 & m_{f} \bar{\kappa} \\
0 & 0 & m_{d} & 0 \\
0 & \kappa & 0 & 1
\end{array}\right]\left\{\begin{array}{l}
\ddot{x}_{1} \\
\ddot{x}_{2} \\
\ddot{x}_{d} \\
\ddot{u}
\end{array}\right\}+\left[\begin{array}{cccc}
c_{1}+c_{2} & -c_{2} & 0 & 0 \\
-c_{2} & c_{2}+c_{d} & -c_{d} & 0 \\
0 & -c_{d} & c_{d} & 0 \\
0 & 0 & 0 & 2 \zeta_{A} \omega_{A}
\end{array}\right]\left\{\begin{array}{l}
\dot{x}_{1} \\
\dot{x}_{2} \\
\dot{x}_{d} \\
\dot{u}
\end{array}\right\}} \\
& +\left[\begin{array}{cccc}
k_{1}+k_{2} & -k_{2} & 0 & 0 \\
-k_{2} & k_{2}+k_{d} & -k_{d} & 0 \\
0 & -k_{d} & k_{d} & 0 \\
0 & 0 & 0 & \omega_{A}^{2}
\end{array}\right]\left\{\begin{array}{l}
x_{1} \\
x_{2} \\
x_{d} \\
u
\end{array}\right\}=-\left\{\begin{array}{c}
m_{1} \\
m_{2}+m_{f} \\
m_{d} \\
\kappa
\end{array}\right\} \ddot{x}_{0}
\end{aligned}
$$

or

$$
[\mathbf{M}]\{\ddot{\mathbf{x}}\}+[\mathbf{C}]\{\dot{\mathbf{x}}\}+[\mathbf{K}]\{\mathbf{x}\}=\{\mathbf{f}\}
$$

Using the modal analysis technique, the governing equation of the structure with TMD and TLCD as shown in Fig. 1 can be expressed in modal coordinate as follows:

$$
\left[\mathbf{m}_{\mathbf{r}}\right]\{\ddot{\mathbf{q}}\}+\left[\mathbf{c}_{\mathbf{r}}\right]\{\dot{\mathbf{q}}\}+\left[\mathbf{k}_{\mathbf{r}}\right]\{\mathbf{q}\}=\{\mathbf{p}\},\{\mathbf{q}\}=[\mathbf{\Phi}]^{-1}\{\mathbf{x}\} \text { and }\{\mathbf{p}\}=[\mathbf{\Phi}]\{\mathbf{f}\}
$$

\section{Numerical Study}

The simulation parameters are shown in Table 1. The building model consists of two lumped masses made of steel plate that connected using four steel beams. The beam length is much longer than its width and thickness[4]. Therefore, these beams can be assumed as the leaf spring. The base of building is fixed to the ground. The ground is excited in horizontal direction.

Table 1 Simulation Parameters

\begin{tabular}{|c|l|l|}
\hline No & \multicolumn{1}{|c|}{ Parameters } & \multicolumn{1}{c|}{ Value } \\
\hline 1 & Mass of the $1^{\text {st }}$ floor $\left(M_{f 1}\right)$ & $3.035 \mathrm{~kg}$ \\
\hline 2 & Mass of the $2^{\text {nd }}$ floor $\left(M_{f 2}\right)$ & $3.010 \mathrm{~kg}$ \\
\hline 3 & Beam length $\left(\ell_{b}\right)$ & $210 \mathrm{~mm}$ \\
\hline 4 & Beam inertia moment $\left(I_{b}\right)$ & $1.667 \mathrm{~mm}^{4}$ \\
\hline 5 & Beam elastic modulus $\left(E_{b}\right)$ & $190 \mathrm{MPa}$ \\
\hline 6 & Beam cross sectional area $(A)$ & $20 \mathrm{~mm}^{2}$ \\
\hline 7 & $\begin{array}{l}\text { Angle between TLCD vertical and } \\
\text { horizontal column }(\beta)\end{array}$ & $90^{\circ}$ \\
\hline
\end{tabular}

The effective space for TLCD can be obtained when the angle between TLCD vertical and horizontal column $(\beta)$ is set $90^{\circ}$ as shown in Table 1 . The design variables used in GA algorithm for TMD are damping coefficient $\left(c_{d}\right)$ and damper mass $\left(m_{d}\right)$. In TLCD absorber, the design variables 
consists of TLCD vertical and horizontal dimension $(H$ and $B)$ and fluid damping due to friction and turbulence $\operatorname{loses}\left(\zeta_{a}\right)$.

The design purpose is optimization of the absorber parameters for achieving the minimum response of the main structure and the absorber motion. Therefore, the parameters of TMD and TLCD are obtained by minimizing the maximum displacement ratio between $2^{\text {nd }}$ floor and ground using Genetic Algorithm (GA) procedure[5]. The absorbers dimensions are used as the constraint parameters during optimization process. Figure 3 shows the schematic diagram of the TMD and TLCD absorbers optimization process using GA.

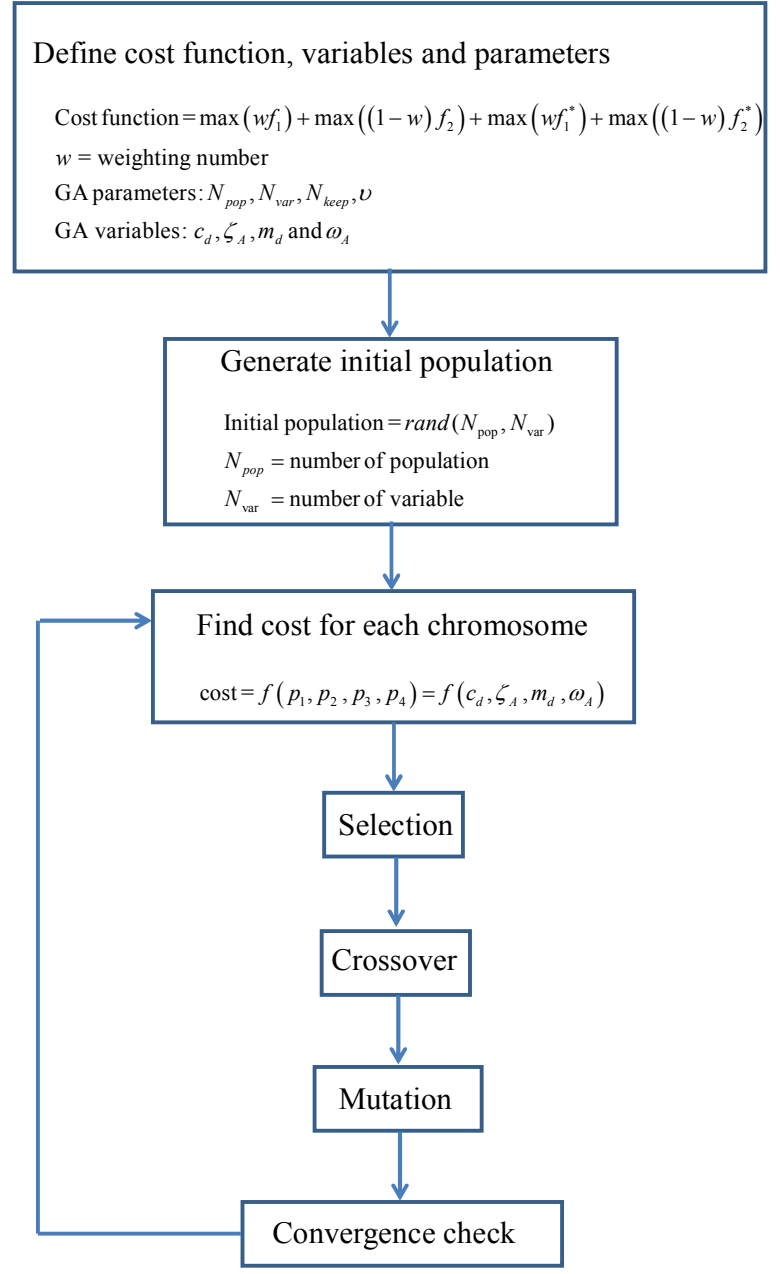

Figure 3. Absorber optimization using GA

The simulation result showing the ratio between the second mass and the base displacement in frequency domain is shown Fig.4. The graph in Fig. 4 indicates that the absorbers are effective in reducing the frequency response of the structure near to its natural frequency.

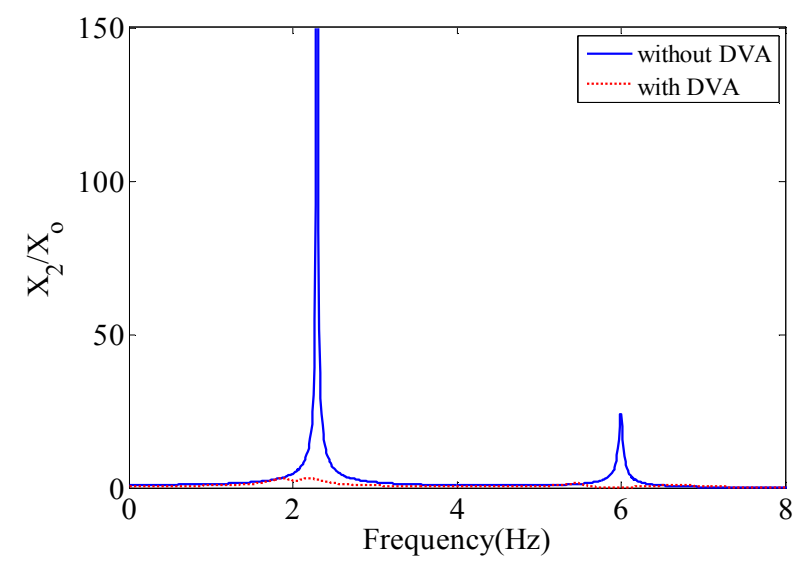

Figure 4 Frequency response ratio between $X_{2}$ and $X_{\mathrm{o}}$ 
The effectiveness of the absorber performance in time domain is evaluated by applying the El-Centro earthquake to the base of the structure. The El-Centro acceleration signal and the response of the second mass are shown in Fig.5. It can be shown that the structure response reduces largely when the absorbers are used. The simulation results of the optimal absorber parameters are shown in Table 2.
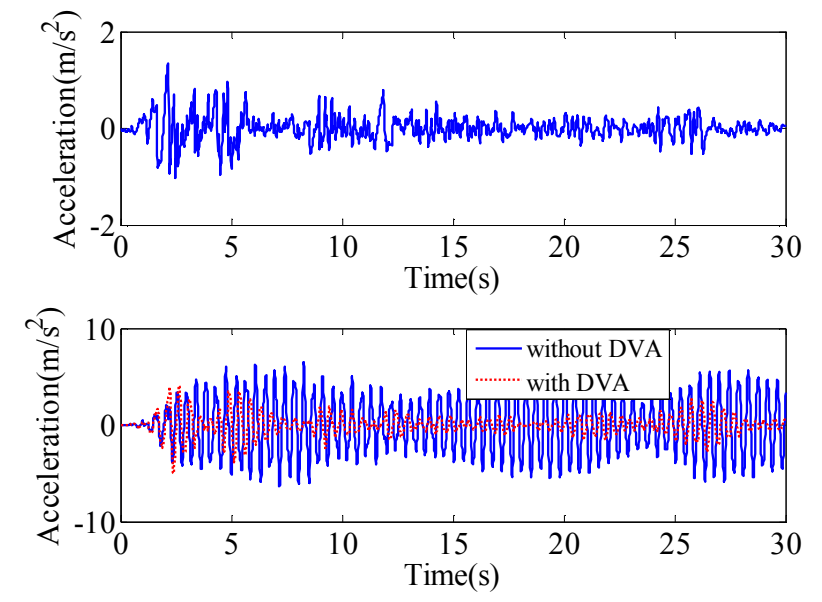

Figure 5 (a) El-Centro earth quake excitation and (b) response of the structure

Table 2 Optimum absorber parameters obtained by GA

\begin{tabular}{|l|l|l|}
\hline Absorber & Parameter & Value \\
\hline \multirow{4}{*}{ TMD } & $m_{d}(\mathrm{~kg})$ & $5.6 \times 10^{-1}$ \\
\cline { 2 - 3 } & $c_{d}(\mathrm{Ns} / \mathrm{m})$ & 2.0 \\
\cline { 2 - 3 } & $k_{d}(\mathrm{~N} / \mathrm{m})$ & $7.38 \times 10^{2}$ \\
\hline \multirow{5}{*}{ TLCD } & $H(\mathrm{~m})$ & $3.1 \times 10^{-2}$ \\
\cline { 2 - 3 } & $B(\mathrm{~m})$ & $5.9 \times 10^{-2}$ \\
\cline { 2 - 3 } & $A_{H}, A_{B}\left(\mathrm{~m}^{2}\right)$ & $3.6 \times 10^{-3}$ \\
\cline { 2 - 3 } & $\zeta_{a}$ & $1 \times 10^{-1}$ \\
\cline { 2 - 3 } & $\beta$ & $90^{\circ}$ \\
\hline
\end{tabular}

Figure 6 shows the relation between cost and population generation in GA simulation. It can be shown from Fig. 6 that the GA simulation becomes stable after 70 generations of population.

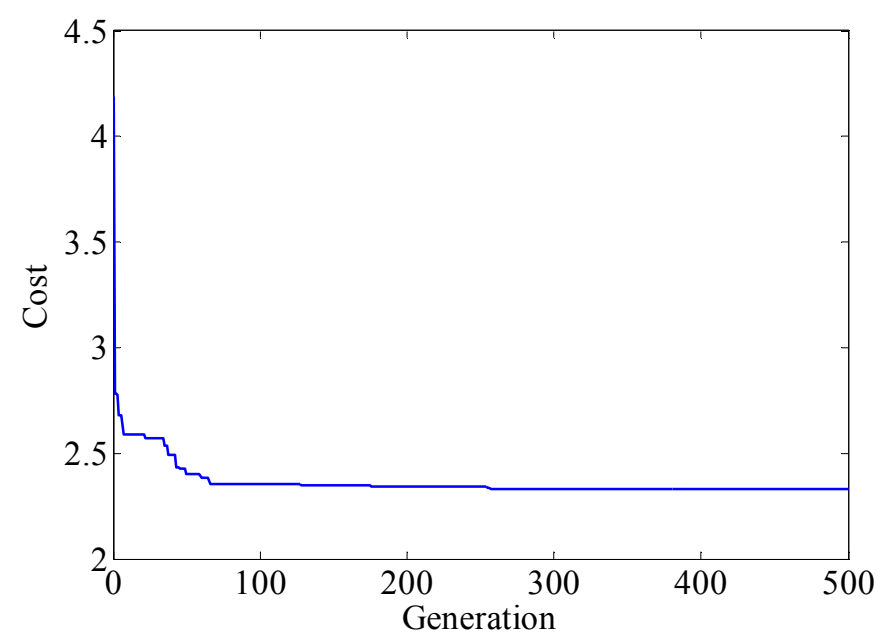

Figure 6 Cost vs generation in GA 


\section{Summary}

Vibration suppression of two-DOF shear structure using TMD and TLCD absorbers has been purposed. The absorbers can reduce the response of the structure in the vicinity of the first and the second natural frequency of the structure. A random search technique using Genetic Algorithm (GA) is used to find the optimal absorber parameters. The simulation results show that GA optimization procedure is effective to obtain the optimal absorber parameters.

\section{Acknowledgment}

Financial support by Hibah Bersaing research fund from The Ministry of Research and Technology and Higher Education of Indonesia with contract number 26/H.16/HB/LPPM/2015 is gratefully acknowledged

\section{References}

[1] M. Rusli, M. Bur and L. Son, Dynamic Vibration Absorber for Squeal Noise Suppression in Simple Model Structures, International Journal of Structural Stability and Dynamic (IJSSD). 15(5), 2015.

[2] J.P. Den Hartog, Mechanical Vibrations: Fourth Edition, McGraw-Hill Book Company, New York, 1956.

[3] M. Reiterer and F. Ziegler, Combined Seismic Activation of a SDOF-Building with a Passive TLCD Attached, $13^{\text {th }}$ World Conference on Earthquake Engineering, Canada, 2004.

[4] L. Son and M. Bur, Effectivity study of Double Dynamic Vibration Absorber on Building Structure due to Seismic Load, Unpublished Hibah Bersaing Research Report, Andalas University, 2013.

[5] R.L. Haupt and S.E. Haupt, Practical Genetic Algorithm, John Willey \& Sons, USA, 2004. 